Article

\title{
Are There Local Versions of Sustainability? Food Networks in the Semi-Periphery
}

\author{
Ewa Kopczyńska@ \\ Institute of Sociology, Jagiellonian University in Krakow, 31-044 Krakow, Poland; ewa.kopczynska@uj.edu.pl \\ Received: 10 March 2020; Accepted: 1 April 2020; Published: 3 April 2020 \\ check for \\ updates
}

\begin{abstract}
The results of many studies of Central and Eastern European food networks suggest that the changes in local food systems are not a delayed repetition of their Western counterparts but have different dynamics resulting from the political and economic circumstances in the countries. To examine the specific sustainability potential of local food networks in Poland, this study compares the collectives based on novel alternative food networks and traditional networks. Drawing on the concept of actant in actor-network theory and content analysis methodology, the study identifies the specificity of these networks. The results show that traditional networks are more focused on the material core of practices, being geographically close, unified, and more specific regarding material actants of the networks. On the other hand, collectives based on Western-style alternative food networks are more widely distributed, reaching out to more abstract and distant actants.
\end{abstract}

Keywords: alternative food networks; Eastern Europe; household sustainability; food culture; actor-network theory; Poland

\section{Introduction}

Sustainability is a political project redefining the distribution of goods, rights, and power and restoring a well-balanced socio-natural order. To ensure the well-being of those whose voices are not heard (peripheral populations, future generations, women, indigenous people, and animals), this project spreads into various communities, regions, social strata, groups, and non-human agents.

This is the starting point for the discussion on optimal local scenarios and ideal forms of "lower-impact practices" in different areas and domains of life. The aim of this article is to understand the role of Central and Eastern European (CEE) food practices within the sustainability debate and to thoroughly examine the concept of the local version of sustainability. It therefore begins by discussing the cultural-political status of CEE food cultures, reviewing the existing conceptualisations of local sustainability, and then identifying the main characteristics of CEE sustainable food practices. The latter are then analysed to describe local sustainable collectives and identify their potential and limitations in the overall sustainability project.

The specificity of CEE cultures comes with their status in the global world system, usually framed as "semi-peripheral": mostly industrialised and relatively stable, having a close economic and political relationship with core countries but, at the same time, always represented as "not quite there yet", as only moderately developed, yet still aspiring and catching up with the countries of the affluent West. Although the last three decades have radically changed the nature of the mutual relations between semi-peripheral CEE and core countries, the narrative of backwardness and constant need for external legitimisation still affect the processes of social change and power distribution. CEE countries are also an arena where a uniform model of sustainability has the chance to be verified and legitimised as a common working model. However, an increasing number of studies on food culture in CEE question the direct transfer of premises and models originating from different geographical contexts. Applying "core" models 
of socioeconomic change (agrarian-industrial-sustainable) to "non-core" contexts results in revealing fractures and undermines the very foundations of planetary sustainability concepts.

The most important responses to the challenges of sustainability within food systems include the concept of alternative food networks (AFN). The high-quality requirements related to the production process [1] have the objective of obtaining natural, not industrially processed food that is usually in keeping with the traditional local economies, contributing to more moderate use of local natural resources, and respecting local cultures and values of local communities. The advantages of shortening the supply chains are increased social integration and trust and ensured availability of fresh food, as well as political ones: a flatter distribution of power than in conventional economies and avoidance of power concentration in the food retail sector. The ideological and cultural significance of alternatives such as food cooperatives, farmers' markets, community-supported agriculture, direct selling, and farm-to-table box schemes is emphasised both in critical food studies and in popular literature questioning the dominant model of industrial food systems [2-5].

Researchers of CEE food systems encounter difficulties with applying the concept of AFNs in the CEE context. The post-socialist framework in which CEE food practices are embedded is characterised by the importance of the informal economy, strong family relations, and low level of generalised trust [6], as well as typical practices oriented towards households' resilience: subsistence farming and small-scale gardening, household food processing, some forms of barter and informal exchange of goods and services, and systems of long-term intergenerational and family obligations [7,8]. A long timeframe tends to be used to legitimise these practices, often referring to tradition as the source of obvious and appropriate solutions. The orientation towards resilience and deep embeddedness in the traditions of local economies has two consequences. First, it links them with AFNs, thus blurring the boundaries between these categories. Second, it makes AFNs an essential—albeit problematic—point of reference in CEE.

Moreover, the temporal dimension, which is a key factor in traditional food practices, makes them very specific and therefore difficult to translate or merge with more recent practices. The vivid intergenerational memory of the Second World War, cyclical post-war crises, narratives, and practices drawn from various stages of the socialist economy, and finally, the experience of economic transition in the 1990s, leave an imprint and constitute a reserve of symbols and practical solutions in contemporary practices. This reservoir of stories, symbols, and legitimations is recorded in the form of tacit knowledge, local know-how, cultural ontologies and identities [8], and nostalgia [9].

These two characteristics of traditional food practices-resilience and strengthening social integration-have fostered their interpretation as actually or potentially sustainable. Some authors have already described CEE versions of sustainability as "vernacular sustainability" [10] or "quiet sustainability" [11,12], analysing local traditional food practices and highlighting their compatibility with the general idea of sustainability and its three pillars. Small-scale food production and preservation, based on traditional methods and limited exploitation of natural resources, result in meeting culturally adjusted nutritional and social needs while maintaining the principle of localness and seasonality and limited environmental impact. The social embeddedness [13] of these informal food economies is underpinned by social bonds, which contribute to preserving cultures and social institutions.

However, it is not only the existence of other quasi-sustainable practices throughout Eastern Europe that is the reason for the questioning of the general applicability of Western forms of sustainability. According to the critics cited above, continuing these practices is not only a habit, a leftover from the tempestuous history of crises, but also an action geared towards the present and future $[10,11,14,15]$. It is a response to the changes taking place in the social, economic, and political landscapes here and now. We can interpret it as a retort and objection to, firstly, the hegemonising neoliberal discourse and, secondly, the acceptance of a trajectory of economies where traditional, pre-capitalist practices must give way to the universal commodification of goods and eventually serve as an inspiration or a legitimising narrative in the form of nostalgia. 
Maria Yotova [16] describes the practices of domestic production of yoghurt in Bulgaria, which became a form of political resistance in the years of transition from a socialist economy to a capitalist one. In the CEE countries, the processes of redefining consumption, and in particular giving food the status of product, have become an arena of negotiation between traditional practices and new Western-type modernisation. At stake in the dispute was the right to categorise both modes of food production as authentic, ecologically clean, and consequently, sustainable. The hygiene, public health, cleanliness, and food safety of traditional vs. industrial food processing were under question $[10,16]$. The relationship between the two forms of short food supply chains took the form of competition, rather than synergy, weakening the practices that contain the potential for sustainability. According to the verdict of one customer of old-style Polish farmers' markets:

"We have two types of organic [food]. We have the organic [food] we buy in a healthy food shop, and everything's more expensive there, like in the West. And we have organic at our markets. The question is how long that will last. I myself sometimes wonder how long." (Interview with middle-age woman at a farmers' market in a small town in southern Poland, 2013) (cited in [17]).

At the institutional level, the inconsistencies of these parallel processes are apparent in the lack of continuity and regularity of food policies. The state of unremitting reform and constant imperative to "keep up with" the changes taking place elsewhere in a (somewhat) more even and ordered way has been described as being a characteristic of the so-called "semi-periphery" [18-20]. The imperative for catching up and imitation instructs "semi-peripheries" to abandon commenced projects, skip stages, forget outdated practices at an accelerated pace, and then again suddenly remember the capitals, structures, institutions, and groups that were hastily abandoned beforehand. Lukáš Zagata et al. [21] describe the political and economic determinants of today's weaknesses of organic agriculture in the Czech Republic. In the early 1990s, the bottom-up development of ecological farms turned out to be incoherent, and at times this process even found itself competing with the dominant vision of economic change. The strong position of the neoliberal project, upon which agricultural policies were based, including the system of subsidies and legal-institutional support, strengthened conventional capitalist agriculture. Local food economies, meanwhile, were at the time deemed competitors of this project and thus lost policy support and funding. Today's educational campaigns and calls to strengthen sustainable food practices are an attempt to rebuild these structures, but their effect is limited, and the "educational" activities themselves are only moderately effective.

If we accept that bottom-up actions and social integration are crucial to social change and that legal-institutional changes must be accompanied by changes in culture [22,23], then the history of the semi-periphery has a greater burden of breaks and disruption to these grassroots processes than the core. The trajectories and logic of changes of CEE systems are not, therefore, a delayed repetition of Western models, but have fundamentally different dynamics from the West, resulting from their political and economic circumstances. As Zagata et al. [21] write, "The organic sectors of the CEE countries seem to be historically embedded in economic transition, rather than in reflexive modernisation, i.e., patterns associated with Western European countries." Therefore, the emergence of sustainable practices needs not be a simple function of wealth, as the prosperity thesis claims [24]. It would also mean that post-material values [25] are not the only source and legitimation of sustainability and that one can justifiably look for sustainable solutions outside of the cultures of core countries [26,27]. (Post-materialist values are belonging, esteem, and intellectual and aesthetic satisfaction as opposed to materialist ones-material sustenance and physical security. Ronald F. Inglehart hypothesised in 1971 that the shift from materialist to post-materialist values is a trend for new generations of Western countries that spent their formative years in prosperity. Existential security is then claimed to be a key factor of moving from material to post-material and self-expression values [28,29]).

Since they are rooted in separate trajectories of change, AFNs and traditional food networks refer to different values and different communications models [30]. However, the contrast between 
traditional forms, with their roots in pre-industrial economic culture, and AFNs as a response to the weaknesses of contemporary global food systems is not confined solely to contrasting temporal horizons. The "carriers" [31,32] of AFNs and traditional practices are different people, groups, and populations. Unlike in certain Western societies, traditional short food supply chains contain an element of coping strategy that is a response to the more or less permanent crises of pre-industrial economies, socialist economics, and capitalism after the events of 1989 [33]. New AFNs, meanwhile, grow out of entirely different motivations and respond to entirely different problems, meaning that they are part of the lifestyles of different social groups with a distinct economic, geographical, and cultural setting. The resultant danger is that access to quality food-local, seasonal, fresh, ethical, and sustainable - is generally limited to people with high economic and cultural capital [34].

East European short food supply chains, however-particularly with regard to production of food for one's own needs, purchases at farmers' markets, and use of informal family food channels (cf. discussion in [35,36]) - encompass much broader social strata, becoming more of a cultural characteristic than a class habitus. Their subsidiary connection to sustainability, so to speak, is not a direct result of people's motivation but of the strategy of the sharing economy and limited consumption of particular resources [37]. Practices have therefore been generated allowing needs to be satisfied while adhering to the general rule of saving scarce foods, while the use of available and renewable goods has increased, especially small-scale techniques of production, processing, and distribution of food. A key element of these techniques is a specific type of social capital, i.e., a system of social relations, dependencies, and mutual obligations, which strengthen the resilience of the community [38].

Economic practices are based on specific cultural framings of capital and resources. Local sustainabilities need to be analysed as multi-layered realities with links of the Weberian type [39], i.e., between economic structures and cultural ones-motivations, attitudes, values, and expectations. They all become arenas of redefinition at the moment of system transformations. In her analysis of the transition from a socialist economy to a capitalist one, using the example of a large privatised enterprise in Poland in the early 1990s, Elizabeth Dunn coined the term "dividual person" to refer to a model becoming part of the past. She pointed to the identity-based, social, and axiological shift that had to occur with this transition, and which was ultimately to lead to the formation of a new person, the "in-dividual" person, who thinks, plans, and calculates in accordance with the new economic and social order [8]. Transformation towards sustainability is therefore sometimes viewed as an analogical change taking place in the identity and mental sphere: specifically as adopting the model of the "I-We" relation rather than the previous "I-It", distance-based one [40] (Ch. 2).

To understand the potential role of "peripheral" variants of resilience in constructing sustainable ecosystems, it is necessary to identify the resources that these variants conserve. It is important to ascertain the effects of sustainable practices: which resources are ignored, which are exploited, and which are renewed and regenerated? Which social structures are strengthened, which technologies are developed, and how are they generally applied? This comprehensive perspective, integrating all pillars of sustainability, demands an approach taking various actors into account: individual humans and social entities, as well as diets, products, plant and animal species, items, and places. Their particular bundle defines specific practices including those that I describe here as traditional and innovative forms of sustainability.

In order to include heterogenous elements of food practices in the analysis, actor-network theory (ANT) is applied. Its theoretical tools help to widen the definition of food practices beyond merely social and cultural phenomena [41]. ANT can also be useful in tracking various layers of "semi-peripherality" of CEE, e.g., "semi-peripheral" technologies, architectures, environments, and species. Finally, the "more-than-human" perspective of ANT provides a methodological insight for sustainability studies, especially when the intersection of cultural and natural processes is examined. Therefore, the study on food-related social practices cannot be limited to social networks and social values, resilience of cultures, cultural identities, humans' and cultures' interests, and well-being. The concepts of actant and collective allow us to introduce non-humans to the analysis of food practices. 
Actants are defined here as acting humans and non-humans which "modify other actors through the series of trials that can be listed thanks to some experimental protocol" [42]. The "minimalism" of this definition means that what actants do precedes what they are. Similarly, the notion of a "carrier" of practice used in practice theories in reference to actors also emphasises the precedence of praxeological "doing" before identity "being" [31]. The very term "actant" is introduced in order to avoid the anthropomorphism implied in the term "actors". A collective is a particular gathering of actants which work together and affect each other, in a way, again, that can be examined with an experimental protocol, which in this study is content analysis [42]. Therefore, the concepts of ANT are used here to observe more than humans (actants) and more than social networks (collectives).

In enquiring about the legitimacy and significance of local versions of sustainability deriving from traditional rather than innovative forms of resilience, I examine the objects that these traditional forms maintain and are maintained by. I compare two types of food collectives, one of which is based on traditional practices and quiet sustainability (i.e., non-market sharing, repairing, gifting, and bartering cultures [12]), and the other on a new type of AFN, inspired by the Western idea of sustainability. The objective of this comparison is to identify those actants which, in the narratives of the people who are carriers of the specific types of practices, are of central importance, the most common, and indispensable for my interviewees' stories. By identifying the most popular actants for a given collective, I am able to answer the question of what specifically these two types of collectives maintain. Which kind of humans and non-humans are particularly strengthened in traditional practices, and which in the new practices of AFNs? Assuming that being included in a collective has a strengthening effect for a given actant, I will identify the similarities and differences between the resilience potential of the two collectives. The critical analysis applies in particular to traditional practices, focusing on the emic concept of "own food" which serves as a legitimation of traditional practices-in comparison to the novelties of AFNs, legitimised by the global concept of sustainability. The analysis discussed below is therefore a contribution to the debate concerning what traditional food practices maintain, what they place in the centre ground, and what they marginalise. It also tackles the question of the consequences of treating CEE traditional "own food" practices as sustainable.

\section{Analysis Design and Methods}

To identify the actants which characterise the two types of short food supply chains, below, I present an analysis of sets of texts that are drawn from the transcriptions of interviews with the carriers of these practices. The interviews took place in the years 2017-2019, with the main characteristics of the sample presented in Table 1. The aim of the research was to collect diverse and in-depth data about different kinds of informal food practices (purposeful sampling). The interviewees differ according to their engagement in those practices. Additional sampling criteria were diversification of location, age, gender, and socioeconomic status.

Table 1. Analysed groups and whole sample overview.

\begin{tabular}{cccc}
\hline & AFN & Traditional & All Interviewees \\
\hline Number of interviews & 11 & 9 & 38 \\
Male/female & $3 / 8$ & $4 / 5$ & $15 / 23$ \\
Location (large city/medium-sized city or small town/village) & $4 / 7 / 0$ & $3 / 1 / 5$ & $23 / 9 / 6$ \\
Economic status (good/moderate/low) & $4 / 6 / 2$ & $3 / 5 / 1$ & $15 / 15 / 8$ \\
Age (less than 35/35-55/more than 55) & $8 / 3 / 0$ & $1 / 4 / 4$ & $15 / 12 / 11$ \\
\hline
\end{tabular}

Two groups were selected from all the 38 interviews and subjected to the analysis presented here. The first group comprises interviews concerning practices identified as traditional and interpreted above as quiet sustainability, vernacular sustainability, or embedded AFNs [15]. These practices are above all informal food production for one's own use in house gardens and city allotments; domestic processing, e.g., baking bread, home production of beer, cold meats, and pickles; and also 
obtaining this kind of homemade products using informal, non-market supply chains, mostly familial and neighbourhood-based. In the whole sample, nine such interviews were identified. The second group of interviews was compiled on the basis of people engaged in new AFNs, especially the members of consumers' food cooperatives, educators, people actively promoting and managing fair-trade and food-sharing initiatives, city farming, and freegans-a total of 11 interviews. The resulting indices for these two groups are interpreted in relation to the whole sample-therefore, all the tables include three columns of calculations. The third column, "all interviews" in Tables 2-4, provides a general point of reference against which "traditional" and "novel" subsamples are analysed. Each of the analysed interviews was divided into few narratives concerning specific food-related practices, and the entire corpus of texts encompassed a total of 304 narratives regarding practices, including 72 narratives of people in traditional structures and 80 narratives of people focused on the new type of AFNs.

First, all the actants were identified from the entire corpus, i.e., all the objects mentioned by the interviewees, irrespective of status: material objects, animals, and people, but also buildings, legal regulations, and state institutions. The criterion for recognition as an actant was firstly agency and playing any role in practices, and secondly their empirical dimension and the chance to observe them directly or with the aid of unambiguous empirical indicators such as smell, movement, the fermentation process, or a criminal prosecution. The theoretical inspiration for definitional decisions was the material-semiotic concept of an actant [35] as one which influences and modifies an actor network, and without which the story and process could not take place. The actants were divided into three groups: humans (other than the interviewee herself), food, and other non-humans. The results of this stage for the AFNs were 751, 1878, and 620 codings respectively, and for traditional practices 1020, 2390, and 1096 codings.

Table 2. Food actants: word frequencies within AFN, traditional, and all interviews.

\begin{tabular}{|c|c|c|c|c|c|c|c|}
\hline \multicolumn{3}{|c|}{ Interviews within AFNs $(n=11)$} & \multicolumn{3}{|c|}{ Interviews within Traditional Networks $(n=9)$} & \multicolumn{2}{|c|}{ All Interviews $(n=38)$} \\
\hline Food & $\begin{array}{l}\text { Frequency } \\
\text { /Interview }\end{array}$ & $\begin{array}{l}\text { Mentioned in } \\
\% \text { Practices }\end{array}$ & Food & $\begin{array}{l}\text { Frequency } \\
\text { /Interview }\end{array}$ & $\begin{array}{l}\text { Mentioned in } \\
\% \text { Practices }\end{array}$ & Food & $\begin{array}{l}\text { Frequency } \\
\text { /Interview }\end{array}$ \\
\hline Meat & 11.2 & 38.8 & Meat & 10.7 & 38.9 & Meat & 10.6 \\
\hline Product & 6.0 & 41.3 & Bread & 8.6 & 23.6 & Vegetable & 6.1 \\
\hline Vegetable & 5.6 & 38.8 & Milk & 6.4 & 27.8 & Bread & 5.5 \\
\hline Milk & 4.1 & 16.3 & Vegetable & 5.7 & 34.7 & Milk & 4.5 \\
\hline Carrot & 3.5 & 17.5 & Lunch & 5.4 & 30.6 & Tomato & 3.8 \\
\hline Food & 3.5 & 16.3 & Egg & 4.9 & 26.4 & Fruit & 3.6 \\
\hline Kasha & 3.1 & 25.0 & Beer & 4.7 & 8.3 & Soup & 3.6 \\
\hline Bread & 2.9 & 16.3 & Cold meat/sausage & 4.6 & 22.2 & Apple & 3.3 \\
\hline Sugar & 2.5 & 17.5 & Potato & 4.6 & 13.9 & Coffee & 3.1 \\
\hline Tomato & 2.5 & 18.8 & Carrot & 4.4 & 18.1 & Egg & 3.1 \\
\hline Fruit & 2.5 & 18.8 & Apple & 4.3 & 18.1 & Cold meat/sausage & 3.0 \\
\hline Dairy & 2.4 & 13.8 & Tomato & 4.2 & 19.4 & Product & 2.9 \\
\hline
\end{tabular}

Table 3. Non-food actants: word frequencies within AFN, traditional, and all interviews.

\begin{tabular}{|c|c|c|c|c|c|c|c|}
\hline \multicolumn{3}{|c|}{ Interviews within AFN ( $n=11)$} & \multicolumn{3}{|c|}{$\begin{array}{l}\text { Interviews within Traditional } \\
\text { Networks }(n=9)\end{array}$} & \multicolumn{2}{|c|}{ All Interviews $(n=38)$} \\
\hline Non-Food & $\begin{array}{l}\text { Frequency } \\
\text { /Interview }\end{array}$ & $\begin{array}{l}\text { Practices } \\
\quad(\%)\end{array}$ & Non-Food & $\begin{array}{l}\text { Frequency } \\
\text { /Interview }\end{array}$ & $\begin{array}{l}\text { Practices } \\
\quad(\%)\end{array}$ & Non-Food & $\begin{array}{l}\text { Frequency } \\
\text { /Interview }\end{array}$ \\
\hline Grocery & 2.2 & 8.8 & Grocery & 5.2 & 20.8 & Grocery & 3.1 \\
\hline Fridge & 1.3 & 13.8 & Chemicals & 3.8 & 22.2 & Fridge & 2.2 \\
\hline Plastic & 1.3 & 13.8 & Jar & 2.8 & 18.1 & Chemicals & 1.7 \\
\hline Fertiliser & 1.2 & 11.3 & Fridge & 2.0 & 18.1 & Jar & 1.4 \\
\hline Animal & 1.2 & 8.8 & House & 1.9 & 18.1 & Diet & 1.2 \\
\hline Compost & 0.9 & 3.8 & Fertiliser & 1.6 & 9.7 & Fertiliser & 1.2 \\
\hline Preservative & 0.9 & 7.5 & Supermarket & 1.4 & 6.9 & Biedronka (discount chain) & 0.8 \\
\hline Packaging & 0.8 & 7.5 & Freezer & 1.4 & 9.7 & Soil & 0.7 \\
\hline Pan & 0.6 & 2.5 & Tree & 1.2 & 6.9 & Animal & 0.7 \\
\hline Ingredients & 0.6 & 3.8 & Ingredients & 1.2 & 5.6 & Bottle & 0.6 \\
\hline Waste bin & 0.6 & 5.0 & Bag & 1.1 & 5.6 & House & 0.6 \\
\hline Bag & 0.6 & 5.0 & Bottle & 1.0 & 12.5 & Supermarket & 0.6 \\
\hline
\end{tabular}


Table 4. Human actants: word frequencies within AFN, traditional, and all interviews.

\begin{tabular}{|c|c|c|c|c|c|c|c|}
\hline \multicolumn{3}{|c|}{ Interviews within AFN ( $n=11$ ) } & \multicolumn{3}{|c|}{ Interviews within Traditional Networks $(n=9)$} & \multicolumn{2}{|c|}{ All Interviews $(n=38)$} \\
\hline Child & 3.9 & 26.3 & Husband & 3.2 & 19.4 & Grandmother & 2.3 \\
\hline Farmer & 2.9 & 17.5 & Person/somebody & 3.1 & 11.1 & People & 2.3 \\
\hline Family & 2.5 & 18.8 & Daughter & 2.2 & 18.1 & Mother & 2.1 \\
\hline Acquaintance & 1.9 & 13.8 & Sister & 2.0 & 15.3 & Acquaintance & 1.4 \\
\hline People & 1.7 & 17.5 & Neighbour & 1.8 & 13.9 & Farmer & 1.2 \\
\hline Vendor & 1.6 & 8.8 & Mother & 1.7 & 15.3 & Son & 1.2 \\
\hline Girlfriend/partner & 1.3 & 11.3 & Family & 1.4 & 18.1 & Person/somebody & 1.1 \\
\hline Friend (female) & 1.3 & 12.5 & Father-in-law & 1.4 & 8.3 & Wife & 1.1 \\
\hline
\end{tabular}

The next step was performed using a content analysis method. After subjecting the codings to lemmatisation, the prevalence of appearances of actants in interviewees' statements was ascertained in two ways. First, the frequency of the three types of actants for the two types of practices was determined. The objective of the analysis was to ascertain those elements of the collective without which the practices could not take place, and I was therefore only interested in the most frequently mentioned actants, restricting the list to 12 items. The indicator of the presence of an actant in this operation is the average number of appearances in a document, that is, a narrative of a single food-related practice. Additionally, for reasons of comparison, the results for the whole, diverse sample group were presented. The aim of the second step was to verify which actants are the most recognised in the narratives of the two groups. Therefore, the percentage of practices where a particular actant is mentioned was also determined. The results of both calculations are presented in Tables $2-4$, for food, human, and non-food actants, respectively.

The above methodological design has a few limitations. The first concerns the nature of the individual in-depth interview (IDI) research method: the practices themselves may be unrecognised in the interviewees' declarations, and their food-related worlds may be intentionally or unintentionally misrepresented. However, standardised content analysis is used only for identifying the actants, and the following qualitative analysis provides a more accurate interpretation of the role they play within practices. A visual anthropology and multi-method approach would help to picture the food system more accurately. Secondly, the content analysis tools applied here are based on the premise of a high frequency of key actants, and thus the adequacy of the results depends on the reflexivity of the research participants. This premise comes from a semiotic-material perspective, where networks of things and links between concepts are parallel. The heterogeneity of data (e.g., observational data) would undermine the following frequency analysis. Thirdly, the limited number of interviews reduces the generalising potential of the results. Since the sampling is purposeful and non-representative, no statistical generalisations are possible. Generalisation can be based only on thorough discussion of the characteristics of the data and of the context of the phenomena in question [43]. Despite these limitations, the research design serves its primary goal, which is providing a more precise and concrete diagnosis of local food practices and their sustainability potential.

\section{Results and Discussion}

The Eastern European context shapes the nature not only of traditional short food supply chains, as presented in the introduction, but also of the AFNs in the region. Eastern European, and particularly Polish, consumers declare a lower level of trust in food market entities but also in other institutions, including food certification systems, than other Europeans [44]. As a result, many local AFNs, e.g., food cooperatives, are inconsistent in obtaining products from eco-certified farms. Also significant here is the context of low wages in Poland, which limit access to certified organic products [36]. In this respect, the social capital and cultural resources often contained in traditional practices are used 
as an equivalent for formalised marketing systems. A further characteristic of the CEE food system is the lower level of recognition of the threats associated with the poor conditions in which farm animals are kept, as well as greater concerns than in Western and Northern Europe regarding the quality, freshness, and health qualities of food [45]. These features of CEE food cultures differentiate AFNs in the region from their Western prototypes. Therefore, the results of this study apply particularly to CEE AFNs.

The following analysis comprises three subsections. In Section 3.1, a list of the most common food actants is presented and discussed. Both subsamples (traditional and AFN practices) are characterised in terms of their edible actants. A similar analysis is then presented with regard to non-food, non-human actants (Section 3.2), and then human actants, i.e., social networks of traditional and ANT practices (Section 3.3). The starting points for all three parts are lists of the frequencies of actants in the interviewees' narratives (Tables 2-4), and then further qualitative interpretation is provided.

\subsection{Food in AFNs and in Traditional Networks}

The food all the respondents spoke about is of a very concrete, practical nature (Table 2). The subject of the interviews was everyday dietary practices, and thus although certain respondents had advanced knowledge concerning various elements of food chains, the focus is on food understood as part of the everyday diet and as specific products. In the group of the most common food items, there were several categories of food. First was fresh unprocessed food, mostly of local origin and all with a strong historical and contemporary position in local diets (apples, carrots, potatoes, eggs, kasha (groats), milk, coffee, and sugar). These foods constitute an important component of the daily diet, and sometimes they are used as a metonymy, referring to the whole groups of goods (e.g., carrots as a representative of all vegetables). They are also used in the context of symbolic culture, including historic, gender, moral, and aesthetic associations.

The next group of the most frequently cited foods is somewhat more general categories (meat, vegetables, dairy), linked by common characteristics, e.g., plant or animal origin, source of supply, storage method, and finally position in the diet: meat, vegetables, and fruit.

Finally, the third category is that of meals and social, material, and symbolic wholes, included in the daily rhythm of consumption patterns. This means the main meal of the day, consisting of soup and a second course, is one of the most central nodes organising everyday activities.

Comparing the frequency of appearance of food items in the two kinds of collectives, traditional collectives are more deeply embedded in everyday practical contexts. Among the 12 most common food actants, the most general category is the meal. People representing traditional food patterns focus on specific products. They grow, buy, exchange, process, and finally consume potatoes, eggs, beer, meat, and bread. They ensure that lunch is ready on time and concern themselves with the freshness of carrots or tomatoes. The perspective of traditional food patterns identifies food through a relatively coherent group of staple goods-meat, bread, milk, eggs, and a few types of vegetables and fruit.

A similar set characterises the interviews with people associated with AFNs. There are not many differences, but they should be interpreted as a small deviation from the traditional menu, in the form of the absence of eggs and cold meats from the list, reduced importance of the main meal as a central consideration defining everyday practices, and the emergence of kasha. This product, although historically the central cereal component of the diet, had since the mid-twentieth century been gradually diminishing in importance. Today, it is making a comeback in healthy diets, restored tradition, and renewed awareness of regional products.

The second characteristic of AFN collectives is the emergence at the top of the list of the actants "product", "food", and "sugar". The relationship with food concerns not only specific edible items but actants located in somewhat different structures-as an element of the market turnover (product) and as a component of food or an additive to it (sugar).

Seeing food as a group of objects with shared characteristics makes it a comparatively uniform category_here, products are seen as part of larger market collectives. Sugar, meanwhile, means descending 
to the level of the ingredients of food, its nutritional properties and effects on the human body. What links the two perspectives, however, is the capacity to form diagnoses at a level going beyond everyday eating practices and fundamentally reaching other orders: on the one hand, the political-economic order (product), and on the other, that of health and technology (sugar, ingredients of food). In the case of AFNs, actants who explicitly enable discussion on the role of food in political orders penetrate to the centre of food narratives.

The enlarged food collective, reinforcing relations with distant food systems and shifting the bridge between individual edible objects with the aid of product categories or sugar, both expands and contracts local food practices. It expands them by making it possible to introduce new criteria and ideas to everyday practices, bringing in innovative solutions and enabling inspiration from previously external, non-transferable food patterns. They make space in a collective for new kinds of actants, open it up to new technologies and, by these linkages, renegotiate the collective's order. Examples might include molecular gastronomy or "discovery" of another superfood or developing market of wild plant food. Yet enlarged food collectives also contract food practices and zoom out by concealing hitherto key differences between individual edible objects. The difference between a turnip and an avocado ceases to be a substantial difference and becomes one of quantity: the amount of nutritious ingredients, carbon footprint, and food miles.

Adopting a broader perspective opens new links of equivalency with which the previous ones must be reconciled. In traditional models of compiling meals, equivalencies (e.g., potatoes and kasha) and complements (e.g., potatoes/kasha + meat/dairy products) resulted from the logic of seasonality and availability.

"You know, there's sour milk, there's a potato, there's crackling, you can put buckwheat with that and I've got two courses, and maybe I'll fry some meat, and if not then cottage cheese with cream is great for me too" (I33: 40-year-old man living in a small village using informal networks for food supply).

In expanded AFN collectives, lines of equivalency, complement, and exclusion take other criteria into account: health and energy value, environmental impact, certificates of organic production etc.:

"Because if we eat, for example, $100 \mathrm{~g}$ of almonds and drink two glasses of Coke, then in terms of calories it will be the same, but in terms of effects on the organism, and the fact that Coca Cola is a drink that consists of sugar, we drink pure sugar. For example, almonds have a lot of calories, but they also have fibre which helps with digestion, so we feel completely different afterwards" (I36: 30-year-old woman from a big city, member of consumers' food cooperative).

A feature that links the two types of collectives is the central position of meat. This plays the role of an accented component [46], i.e., one that defines social events, meals, and all other food-related practices. Meat defines shopping strategies, determines the time for preparing a meal, and designates its status. But the prevalence of meat in the interviews does not mean that it was accepted unreservedly. Meat is at the centre of the narratives because it is also a difficult product: uncertain in terms of quality, easily going off and potentially impure, and problematic with regard to health issues.

It is no surprise that ethical and environmental issues appear in the context of AFNs regarding the climate threats associated with mass meat production. But AFN collectives and critics of the global food system are not the only source of the dubious status of mass production and the "I-it" relationship on which it is founded. The criticism expressed within traditional collectives is of a different nature: it draws upon personal experiences, bodily sensations, and moral intuitions ("it doesn't feel right"). It gains legitimacy in references to the model of moral-material relations between humans and animals: 
"I'm concerned about production of meat and eggs, for example, because the production method is a big machine where what matters isn't the individual, but profit from the whole. [ ... ] I have a hen I've raised for the last ten years, and it's still there. Sometimes I've even taken the hen into the garden and it's pecked around. I was weeding and plucking, and it was pecking, and it was great, the two of us pecking around." (I1: woman in her twenties engaged in permaculture methods).

This placing of meat and animals in a domestic context and reference to one's own experience of personal relationships and to the feeling that "something's wrong", proves to be a potential source of limited impact practices. It is therefore possible to apply other legitimations than the global idea of sustainability and to construct other collectives than counter-conventional alternatives, giving hope for sustaining the human and non-human world, but with coexisting and cooperating humans.

Analysis of food actants within traditional and AFN collectives results in understanding how these two sustainability projects develop. The former is based on a relatively limited circle of goods valued by their unique, cultural qualities, gathered around habitual everyday consumption events, i.e., homemade meals and particular human-animal, more-than-economic relations. The latter is densely linked to distant localities, health and economy discourses via more abstract, relational qualities: ingredients, nutritional values, and characteristics of the supply chain. These abstract links help AFN practices to penetrate and influence global networks and vice-versa, to be easily influenced by new technologies, new types of actants, and political projects. In the following paragraphs, the non-food actants—non-human and human—are similarly explored.

\subsection{Around Food: Objects}

Actants not belonging to the class of either food or humans comprise the most dispersed part of the collective (Table 3). The majority of the list items appear only in selected interviews and selected practices. This dispersal applies in particular to the narratives of AFN members: the only objects that appear in more than $10 \%$ of practices of these people are the fridge, plastic, and fertiliser.

The fridge has a similar status in the group of traditional and AFN consumers-it is both one of the most frequent and one of the most universal objects. It is not only a place of domestic food storage but also occurs in narratives as a cultural symbol of storage, resources, reserves, affluence, and excess.

Traditional consumers commonly and often also refer to other elements of domestic distribution networks: the home itself, the freezer, bags, and jars and bottles in which food is kept and processed and which make it available to people. As with food actants, the narratives are focused on private practices, identifying the elements of the domestic microcosm with more precision and detail, and concentrating on them to a greater extent. In collectives of traditional practices, the distant, general, and abstract are marginalised.

The exception is chemicals. These are a typical negative point of reference for "fresh food" and a criterion for distinguishing good, natural food from food deriving from an inappropriate socio-technological order [17]:

"There are definitely chemicals, because all the produce is accelerated. They have to be accelerated by chemicals to grow earlier and look all right. Because the appearance of my fruit and veg is completely different" (I23: 60-year-old woman producing most of her food herself in her allotment).

In the interviews, therefore, chemicals have the function of demarcation criteria for food quality, but they also mark the symbolic boundary between two orders of food production; they might be used as a metaphor for what traditional practices resist. Chemicals are present in collectives as a means for recognising what should be excluded and practising this exclusion. The collective's answer to the threats of a "chemicalised" food system is different for traditional and AFN practices. The former's focus is set on homemade food production, processing, and storage technologies, whereas the latter 
try to address the problem from a more systemic angle. Hence, the frequent references to plastic and compost can be interpreted as an AFN's collective's concern about packaging technologies and global food-related waste economies.

The strength of traditional collectives in comparison to AFNs is their relative cohesiveness and focus, evident specifically in the frequency and prevalence of actants. In the narratives I studied, the micro-world of the household, household production methods, processing, and patterns of food consumption is regular, cohesive, and concentrated. Yet this concentration and focus is not evident in the interviews with people involved in AFNs. Despite the similarity of the discourse used by AFN people and general references to similar ideas and similar motivations-sustainable development, a fair and ethical food system with a respect for resources, the struggle with the problems of excessive waste production, food packaging, and non-biodegradable materials-AFNs are much more disparate in terms of both food and non-food actants, recognisable as an element of their members' everyday practices. Similarly to food actants, non-food actants in AFN collectives reach out to more distant, even global, systems of distribution and waste disposal.

\subsection{Social Networks for and around Food}

A somewhat different, more complex picture emerges from analysis of the frequency of human actants within collectives of AFNs and traditional practices (Table 4). In both groups, children are the most often mentioned actants, appearing in $26 \%$ of practices. The central role of children in food collectives is present in taste preferences and health, and as an important factor of the rhythm of meals. It is present in the changing eating habits in the biographies of adult members of the households when everyday routines change with children appearing or leaving their parents' home. Children are central nodes for food-related practices in the way food production and consumption is adapted to their needs, and the presence of children triggers or limits particular activities:

"You know what, sometimes I prepare meat at home. I arrange to meet my sister, because we have children of similar ages, the children run around in the yard, we drink coffee and the meat curing goes on" (I3: 45-year-old woman producing homemade sausages, pickles, and jams).

The fundamental difference between traditional social interaction and that of AFNs is again the former's focus on family and neighbours' relations. The food collective described in narratives about traditional practices is above all—at the interpersonal level—husband, daughter, sister, mother, grandmother, wife, and close neighbours. This is the world of people (mostly women) with whom the most lasting relations are maintained-dense, full of mutual obligations and favours, differing from the rules of market exchange, and, to a certain extent, autonomous social microsystems. Their operation is defined by the positions of children and husbands, and then women, including wives, from the close family. In traditional collectives, food-related practices "circulate" among particular, limited groups of people, and food travels along family bonds.

AFNs, meanwhile, though not detached from family structures, discern a significant presence of other people, such as the farmer, friends, colleagues, and of course AFN actants, which in the analysed interviews usually meant food cooperatives. AFNs use social relations to join home food collectives with more distant spheres, especially with acquaintance networks and with market systems-both conventional and organic ones. Furthermore, the data presented here show that these weaker interpersonal ties are critical for functioning in AFN models. Such social interactions and references to human actants in short food supply chains (farmer, cooperative) are elements without which a narrative on a cooperative or food-sharing initiative is impossible. Then, following the ANT line of interpretation, the hypothesis is that AFNs can actually strengthen the more dispersed, global communities of food practices and that the current proliferation of AFNs in CEE countries can result in redefining family relations. Novel alternative food practices can have a considerable impact 
on family patterns, especially in relation to households' microeconomies and informal systems of exchange - thanks to their ability to build a bridge between the family and more distant communities.

\section{Conclusions}

This article presents a content analysis and qualitative analysis of interviews with people involved in traditional food practices and novel AFNs. The objective of the analysis was to describe the food collectives in which these practices take place by naming the actants from three groups-food, humans, and other non-human actants-appearing most frequently and most prevalently in the interviews. According to the premises of the ANT's concept of actants, on the one hand, these most common elements determine the various practices, while on the other, they are reinforced and stabilised by these practices. Therefore, the key actants in food practices also define how they are resilient and what they maintain, reproduce, and reinforce. This research is a step towards identifying the foundations, determinants, and potential of local forms of sustainability in CEE in a more precise way than in previous studies.

This study draws upon existing literature on traditional food practices in the specific CEE context. It continues with the main results of this research, especially conceptualising a local model of sustainability different from the Western one and providing some unique ethics, routines, and economies $[10,11,15,21]$. What is original is the theoretical and methodological background, allowing content analysis to be combined with qualitative interpretation to reveal the collective and more-than-human aspect of food practices. Designing a new experimental protocol, based on new empirical data and content analysis with the use of ANT concepts, provides a more specific characterisation of local sustainability models and allows the formulation of new hypotheses about the dynamics of local food systems. The methodological output of the study also tests the semi-standardised design for further research of food practices.

The most important characteristic of networks based on traditional practices is their focus on a very concrete non-human environment. These objects (both food and non-food) are situated in everyday, domestic spheres in the scope of everyday activities, identifiable in terms of their material properties and geographically close. They constitute the material core of traditional practices, reinforced through repetitive, rhythmic, and habitual activities: shopping, preparing meals, family life, small-scale food production, processing, storage, and consumption. There is no such concentration of particular food and non-food items in AFNs. The practices inspired and motivated by the global idea of sustainability and responding to global threats are considerably broader and less focused. They are oriented towards more general food regimes and recognise more geographically distant actants and those in food chains-including animals, processes of decomposition, and waste management. These results shed new light on our understanding of how particular material objects are entwined in or excluded from traditional and novel practices. The central role of a few local food products has been indicated by several researchers (e.g., $[16,47])$, but the content analysis presented here enables me to identify them precisely as distinctive from AFN networks.

Another characteristic of traditional and innovative collectives helps one to understand their distributional potential. Traditional ones conserve and are maintained by family networks, whereas an important property of AFNs recognised in this study is their orientation towards the extended human community: distant acquaintances, farmers, and institutional entities in the guise of informal communities, e.g., cooperatives. An AFN therefore works as a more disparate network, but one strongly based on human actants. This also helps to explain how novel networks are so effective in "colonising" different socio-economic contexts with their ideas and values and becoming the medium for a specific cultural capital and class habitus [11,34,35].

The results also make it possible to form several hypotheses specifying the concepts of local versions of sustainability emerging from and making use of the resources of traditional food practices. Comparing local sustainability practices to novel ones reveals how hermetic and "self-sufficient" they are in terms of the model of social relations. AFNs, based on global ideas of sustainability, meanwhile, reproduce broader, looser relations. AFNs can then be more effective in strengthening other social ties 
than family ones and in building communities where the family model-i.e., permanent, non-market, intergenerational, and complex-is not, for different reasons, dominant.

The closeness of the material objects characterising traditional networks translates into sustainable use of material resources. An example of such restrained practices embedded in economies of limited resources is meal structure making it possible to substitute equivalent ingredients while maintaining the status of a full meal, the habit of stocking up, processing and storing food using reusable material resources (jars, bottles, fermentation), and social resources (family exchange networks).

Meanwhile, traditional social networks, because of their local nature, have limited capacity to evoke and affect distant actants. AFNs form supralocal policies and solutions aspiring to global legitimacy by affecting geographical actants and working on various scales, not only that of everyday meals. They are able to refer to global policies as well as technological, economic, and health-related processes.

What connects the two types of networks and can become an arena of cooperation is, firstly, particular food items that are inherent to the local context and form the basis of everyday eating practices. These include some local fruits and vegetables, bread, and meat. In the processes of cultural adaptation and redefinition of local cuisines, these products revolve between traditional and new networks and can potentially become a bridge between the ideas and actions of global and local sustainability. Secondly, family ties can also become such a bridge, not necessarily reproducing old structures and roles, but as a model and inspiration providing the impetus for creating a new type of communities. Thirdly, the role of different kinds of food containers-from fridges to bags and jars-should be recognised as crucial non-human actants of households' food collectives and therefore the ones that determine the potential and the outcome of local sustainable practices.

To summarise, the results of this study provide a starting point for developing further sustainable solutions in peripheral and "semi-peripheral" areas. By comparing novel and traditional sustainable collectives, this study helps to integrate our understanding of different paths to sustainable food systems. More studies are needed to generate a comparative perspective, especially on different local contexts. In addition, further research focused on the limitations, exclusions, and disadvantages of local traditions would help to identify which resources, both material and social, are overlooked, and how and when traditional informal economies undermine the goals of a sustainable future. The example presented here is then considered to be a step towards formulating more localised and embedded policies of sustainability.

Funding: This research was funded by the National Science Centre (Poland), grant number 2017/25/B/HS6/00617.

Conflicts of Interest: The author declares no conflict of interest. The funders had no role in the design of the study; in the collection, analyses, or interpretation of data; in the writing of the manuscript; or in the decision to publish the results.

\section{References}

1. Forssell, S.; Lankoski, L. The sustainability promise of alternative food networks: An examination through "alternative" characteristics. Agric. Hum. Values 2015, 32, 63-75. [CrossRef]

2. Goodman, D.; DuPuis, E.M.; Goodman, M.K. Alternative Food Networks: Knowledge, Practice, and Politics; Routledge: Abingdon, UK, 2012; ISBN 0-203-80452-X.

3. Spaargaren, G.; Oosterveer, P.; Loeber, A. Food Practices in Transition: Changing Food Consumption, Retail and Production in the Age of Reflexive Modernity; Routledge: Abingdon, UK, 2013; ISBN 1-136-48544-9.

4. Blay-Palmer, A. Food Fears: From Industrial to Sustainable Food Systems; Ashgate Publishing, Ltd.: Farnham, UK, 2008; ISBN 0-7546-7248-4.

5. Pollan, M. The Omnivore's Dilemma: The Search for a Perfect Meal in a Fast-Food World; Bloomsbury Publishing: London, UK, 2009; ISBN 1-4088-0725-4.

6. ESS Round 8: European Social Survey Round 8 Data. Data File Edition 2.1. 2016. Available online: https://www.europeansocialsurvey.org/data/download.html?r=8 (accessed on 2 April 2020).

7. Caldwell, M.L. Not by Bread Alone: Social Support in the New Russia; University of California Press: Berkeley, CA, USA, 2004; ISBN 0-520-93725-2. 
8. Dunn, E.C. Privatizing Poland: Baby Food, Big Business, and the Remaking of Labor; Cornell University Press: Ithaca, NY, USA, 2004; ISBN 0-8014-8929-6.

9. Todorova, M.N.; Gille, Z. Post-Communist Nostalgia; Berghahn Books: New York, NY, USA, 2010; ISBN 978-1-84545-671-9.

10. Mincyte, D. How milk does the world good: Vernacular sustainability and alternative food systems in post-socialist Europe. Agric. Hum. Values 2012, 29, 41-52. [CrossRef]

11. Smith, J.; Jehlička, P. Quiet sustainability: Fertile lessons from Europe's productive gardeners. J. Rural Stud. 2013, 32, 148-157. [CrossRef]

12. Smith, J.; Kostelecký, T.; Jehlička, P. Quietly does it: Questioning assumptions about class, sustainability and consumption. Geoforum 2015, 67, 223-232. [CrossRef]

13. Granovetter, M. Economic action and social structure: The problem of embeddedness. Am. J. Sociol. 1985, 91, 481-510. [CrossRef]

14. Daskon, C.D. Cultural resilience-The roles of cultural traditions in sustaining rural livelihoods: A case study from rural Kandyan villages in Central Sri Lanka. Sustainability 2010, 2, 1080-1100. [CrossRef]

15. Goszczyński, W.; Śpiewak, R.; Bilewicz, A.; Wróblewski, M. Between Imitation and Embeddedness: Three Types of Polish Alternative Food Networks. Sustainability 2019, 11, 7059. [CrossRef]

16. Yotova, M. The "goodness" of homemade yogurt: Self-provisioning as sustainable food practices in post-socialist Bulgaria. Local Environ. 2018, 23, 1063-1074. [CrossRef]

17. Kopczyńska, E. Co to jest jedzenie naturalne? Socjonatura na targowisku. Stud. Socjol. 2015, 219, 181-203.

18. Chase-Dunn, C. Rise and Demise: Comparing World Systems; Routledge: Abingdon, UK, 2018; ISBN 0-429-96170-7.

19. Shields, S. CEE as a New Semi-Periphery: Transnational Social Forces and Poland's Transition. In Globalization and the 'New'Semi-Peripheries; Springer: Berlin/Heidelberg, Germany, 2009; pp. 159-176.

20. Grzechnik, M. The Missing Second World: On Poland and Postcolonial Studies. Interventions 2019, 21, 998-1014. [CrossRef]

21. Zagata, L.; Hrabák, J.; Lošt'ák, M. Post-socialist transition as a driving force of the sustainable agriculture: A case study from the Czech Republic. Agroecol. Sustain. Food Syst. 2019, 44, 1-20. [CrossRef]

22. Sztompka, P. Looking back: The year 1989 as a cultural and civilizational break. Communist Post-Communist Stud. 1996, 29, 115-129. [CrossRef]

23. Sztompka, P. From East Europeans to Europeans: Shifting collective identities and symbolic boundaries in the New Europe. Eur. Rev. 2004, 12, 481-496. [CrossRef]

24. Franzen, A.; Meyer, R. Environmental Attitudes in Cross-National Perspective: A Multilevel Analysis of the ISSP 1993 and 2000. Eur. Sociol. Rev. 2009, 26, 219-234. [CrossRef]

25. Inglehart, R.; Welzel, C. Modernization, Cultural Change, and Democracy: The Human Development Sequence; Cambridge University Press: Cambridge, UK, 2005; ISBN 0-521-60971-2.

26. Dolenec, D.; Domazet, M.; Ančić, B. Why power is not a peripheral concern: Exploring the relationship between inequality and sustainability. In Sustainability Perspectives from the European Semi-Periphery; Domazet, M., Marinović Jerolimov, D., Eds.; Institute for Social Research: Zagreb, Croatia, 2014; pp. 145-172.

27. MacGregor, S.; Walker, C.; Katz-Gerro, T. It's what I've always done: Continuity and change in the household sustainability practices of Somali immigrants in the UK. Geoforum 2019, 107, 143-153. [CrossRef]

28. Inglehart, R. The silent revolution in Europe: Intergenerational change in post-industrial societies. Am. Polit. Sci. Rev. 1971, 65, 991-1017. [CrossRef]

29. Inglehart, R.F. Changing values among western publics from 1970 to 2006. West Eur. Polit. 2008, 31, $130-146$. [CrossRef]

30. Kopczyńska, E. Novelty with a Traditional Twist: Food Co-Operatives as Short Food Chains in the Global Network. In Food and the Internet; Krawczyk-Wasilewska, V., Lysaght, P., Eds.; Springer: Berlin/Heidelberg, Germany, 2015; pp. 125-132.

31. Reckwitz, A. Toward a theory of social practices: A development in culturalist theorizing. Eur. J. Soc. Theory 2002, 5, 243-263. [CrossRef]

32. Shove, E.; Pantzar, M.; Watson, M. The Dynamics of Social Practice: Everyday Life and How it Changes; Sage: Thousand Oaks, CA, USA, 2012; ISBN 1-4462-5817-3.

33. Alber, J.; Kohler, U. Informal food production in the enlarged European Union. Soc. Indic. Res. 2008, 89, 113-127. [CrossRef] 
34. Bilewicz, A.; Śpiewak, R. Enclaves of Activism and Taste: Consumer Cooperatives in Poland as Alternative Food Networks. 2015. Available online: https://www.researchgate.net/publication/290471782_Enclaves_of_activism_ and_taste_Consumer_cooperatives_in_Poland_as_alternative_food_networks (accessed on 2 April 2020).

35. Spilková, J.; Fendrychová, L.; Syrovátková, M. Farmers' markets in Prague: A new challenge within the urban shoppingscape. Agric. Hum. Values 2013, 30, 179-191. [CrossRef]

36. Kopczyńska, E. Economies of Acquaintances: Social Relations during Shopping at Food Markets and in Consumers' Food Cooperatives. East Eur. Polit. Soc. 2017, 31, 637-658. [CrossRef]

37. Klocker, N.; Gibson, C.; Borger, E. Living Together but Apart: Material Geographies of Everyday Sustainability in Extended Family Households. Environ. Plan. Econ. Space 2012, 44, 2240-2259. [CrossRef]

38. Jackson, P.; Everts, J. Anxiety as social practice. Environ. Plan. A 2010, 42, 2791-2806. [CrossRef]

39. Weber, M. The Protestant Ethic and the Spirit of Capitalism; Routledge: Abingdon, UK, 2013; ISBN 1-135-97398-9.

40. Manstetten, R. Sustainability, culture and personal virtues. In Personal Sustainability: Exploring the Far Side of Sustainable Development; Routledge: Abingdon, UK, 2018.

41. Warde, A. The Practice of Eating; John Wiley \& Sons: Hoboken, NJ, USA, 2016; ISBN 0-7456-9174-9.

42. Latour, B. Politics of Nature; Harvard University Press: Cambridge, MA, USA, 2004; ISBN 0-674-01289-5.

43. Payne, G.; Williams, M. Generalization in qualitative research. Sociology 2005, 39, 295-314. [CrossRef]

44. Vittersø, G.; Torjusen, H.; Laitala, K.; Tocco, B.; Biasini, B.; Csillag, P.; de Labarre, M.D.; Lecoeur, J.-L.; Maj, A.; Majewski, E.; et al. Short Food Supply Chains and Their Contributions to Sustainability: Participants' Views and Perceptions from 12 European Cases. Sustainability 2019, 11, 4800. [CrossRef]

45. Food-Related Risks. Eurobarometer S, 2010. Available online: https:/ec.europa.eu/commfrontoffice/ publicopinion/archives/ebs/ebs_354_en.pdf (accessed on 1 April 2020).

46. Douglas, M. Deciphering a meal. Daedalus 1972, 101, 61-81.

47. Ries, N. Potato ontology: Surviving postsocialism in Russia. Cult. Anthropol. 2009, 24, 181-212. [CrossRef]

(C) 2020 by the author. Licensee MDPI, Basel, Switzerland. This article is an open access article distributed under the terms and conditions of the Creative Commons Attribution (CC BY) license (http://creativecommons.org/licenses/by/4.0/). 